\title{
THE COMPOSITION AND ROLE OF CONVERGENT TECHNOLOGICAL REPERTOIRES IN AUDIOVISUAL MEDIA CONSUMPTION
}

Cédric Courtois, Lieven De Marez, and Pieter Verdegem

Running head: 'Audiovisual media technology repertoires'

COURTOIS, Cédric* (cedric.courtois@ugent.be, +32 926491 54) (Corresponding Author)

DE MAREZ, Lieven* (lieven.demarez@ugent.be, +32 926468 85)

VERDEGEM, Pieter* (pieter.verdegem@ugent.be, +32 926467 15)

* Research Group for Media \& ICT (MICT, www.mict.be), Department of Communication Sciences, Faculty of Political and Social Studies, Ghent University-Belgium. Korte Meer 7/9/11, BE-9000 Ghent-Belgium. MICT is a part of iMinds (www.iminds.be). 


\title{
THE COMPOSITION AND ROLE OF CONVERGENT TECHNOLOGICAL REPERTOIRES IN AUDIOVISUAL MEDIA CONSUMPTION
}

\begin{abstract}
This mixed-method research focuses on the growing appropriation of multiple screen devices for audiovisual media consumption. Based on survey measures, we distinguish thee patterns: (a) maintaining the status quo, by mainly drawing upon television, (b) broadening up the repertoire, by extending television with computers and mobile devices, or (c) even replacing television by a computer. Next, we draw upon insights form niche theory, rationalizing media choices in terms of competing gratifications. This perspective is however too one-sided, as our results indicate that habit is a much stronger explanatory variable, especially when a broad range of devices is appropriated. In a follow-up qualitative study, based on Q-methodology, we found that the orientations towards what people seek in audiovisual technologies are only mildly contingent with specific technology appropriation. This problematizes the very substance of niches in the audiovisual: as technologies are capable of the same things, their discriminating power is declining. Hence, in future applications of niche theory, gratifications and habits of communication modes (what people do with media technologies) should be taken into account, rather than media as tied to a specific technology. Niche theory's core remains, but its applications should be updated to theoretical insights matching the evolving media environment.
\end{abstract}

\section{INTRODUCTION}

Due to digitization, audiovisual media content has become a liquid asset in today's media ecology. It is a transferable commodity that is not inherently tied to a platform, but is subjected to managerial will, 'streaming' it through platforms as a corporate strategy, either through plain re-mediation, or adaptation in all possible directions (Murray, 2003; Jenkins, 
2006). Nowadays, dissemination takes place on a variety of platforms, ranging from linear broadcast to video-on-demand through interactive television, or web casting; not to forget (illegal) peer-to-peer circuits (Smith, 2009). At the same time, we have witnessed how various screen media have converged in terms of their affordances. Audiovisual materials are not only displayed by the television set, but also by various handheld devices, as well as the personal computer in all its forms. Most of these devices are commonplace in the average household and, by implication, most people have a myriad of options to engage with audiovisual content. Nevertheless, as previous research has pointed out, there is a large gap between the adoption diffusion of the affording screen devices, and the use diffusion in terms of audiovisual content consumption. More specifically, a large majority, living in an overall media-rich household, is not embracing the affordance of regularly watching audiovisual materials on their many devices (Courtois, D'heer, \& Schuurman, 2012; also see Shih and Venkatesh, 2004 for a more general discussion on adoption and use diffusion).

In this paper, the aim is to gain insight in the role of screen technology in audiovisual media consumption. Obviously, audiences have to some extent diversified their means to engage with audiovisual materials. More specifically, various bridges are present between devices, bringing about appropriation patterns that have remained under-researched (Hess, Ley, Ogonowksi, Wan and Wulf, 2001). The emerging questions are of what these patterns consist, and - if so - why such diversity exists. Hence, a first objective is to look into these patterns, approaching them as framed within people's audiovisual media consumption habits. In doing so, we elaborate on niche theory (Dimmick, Kline, \& Stafford, 2000; Ramirez, Dimmick, Feaster, \& Lin, 2008), that draws upon gratifications research to generally explain why new media displace or co-exist with older media, and use it to frame our study on the appropriation of different screen technologies. However, niche theory assumes conscious deliberation on the users' behalf, explicitly comparing pros and cons. Media consumption 
behaviour, however, has repeatedly been appointed as habit-driven (LaRose, 2010). As such, in an attempt to reconcile both perspectives, our first research question (RQ 1a) first inquires whether patterns of screen technology appropriation are distinguishable and then (RQ 1b) focuses on the balance between motivation and habit strength in explaining consumption frequency within these patterns.

The second objective is to gain insight in the construction of audiovisual screen technology. More specifically, we frame this in the context of the everyday routine practices and social relations, rather than just taking into account the objective properties of technologies. The goal is to reconstruct a small group of participants' cognitive schemas with regards to audiovisual technologies, or how they make sense of screen technology niches. Drawing upon Q-methodology as a structuring device, a typology of positions towards the most-valued properties of audiovisual technologies will be derived. As such, we answer a second twofold research question, i.e. what do people consider must-have affordances of an audiovisual technology, and how does this relate to the devices they use? As such, we seek an understanding of why differential repertoires of technologies are appropriated.

\section{The theory of the niche}

Through out history, new media technologies in the broadest possible sense have emerged consistently. As such, audiences have always been inclined to select media, and form cross-medial consumption patterns. According to niche theory (Dimmick, et al., 2000; Ramirez, et al., 2008), new media are in constant competition with older and more established ones, in order to attract audience members' limited resources such as time, effort and money. The theory of the niche postulates that each medium should hold unique gratification opportunities in order to acquire and maintain its niche. This means that it is assumed that each medium has the ability to offer certain benefits, albeit differential in the breath of the spectrum of gratifications it delivers. A niche can be very general (broad in scope) versus 
much more specialist (narrow in scope) in contrast with other media. When there is an overlap in niches, that is, when the benefits are equal for two or more media, these media directly compete with each other because they could (partially) substitute one another (i.e. competitive superiority, which lead to competitive displacement, or even competitive exclusion). On the other hand, in case of a minor overlap, there is reason to suspect a peaceful co-habitation. That is using both media as complements, next to each other.

The theory of the niche has been proven useful to study - among others - the gratification niches of interpersonal media (Dimmick, et al., 2000; Ramirez, et al., 2008), news media (Li, 2001), and entertainment media (Dimmick, 2003). A standard approach is to perform a pilot study in which all possible gratifications are listed. In fact, the niche approach assumes that there is no pre-given set of gratifications, so that for each study, possible gratifications need to be derived empirically. In the subsequent main study, these positive attributes are scored for the media involved in the study. Next, in the phase of analysis, fixed formulas are used to calculate niche breadth, overlap and superiority, which indicate the range of gratification, the coincidence of gratification, and the strength of one medium as opposed to another (Dimmick, et al., 2000).

Niche theory certainly makes sense, and has been applied successfully. Still, our topic of research is somewhat different. Rather than looking into media itself, we focus on the supporting screen technologies. More specifically, we adopt a triple articulation perspective to frame media. That is, considering media as the composition and dynamic interplay of three distinct, and in practice increasingly varying elements: (a) an affording physical, technological object, (b) a conveyer of meaningful media texts, and (c) part of a context it mutually shapes (Courtois, Verdegem, \& De Marez, in press). The reason we single out the affording object, is because of the seeming convergence. On the one hand, screen devices increasingly afford similar practices, while on the other, their diversity in subjective 
capabilities is apparent (cf. supra). The question rises whether a 'one size fits all' approach like niche theory is helpful. It is plausible to find diversity in what technologies are handled, and how they are handled to attain certain gratifications.

Moreover, there are some issues that need special consideration. These boil down to the core assumption of rationality. Niche theory presumes that respondents in the pilot study are able to elicit and disclose a full range of gratifications, without any help to activate the relevant cognitive schema. Furthermore, empirical niche studies only consider conscious motivation to engage in media consumption. What it ignores is that although respondents might be inclined to agree with the presented attributes because those are commonly associated with media. At the same time, they could still use other media out of habit. In other words, it is fairly possible that one communication technology is more gratifying to use, whereas people consistently revert to another because it is something they are unconsciously used to. As such, like appointed in previous criticisms on U-and-G (Ruggiero, 2000), the explanatory power of gratifications as such is quite limited (LaRose, Mastro, \& Eastin, 2001).

Nevertheless, the idea of competing media is compelling and especially relevant in today's cross-media ecology. Still, habit - reflecting a stable behaviour - is an overall factor in explaining media consumption (LaRose, 2010). Hence, we are confronted with the fluid opposition of conscious motivation (as proposed by niche theory) and habit, reflecting unconscious, crystallized motivation. Looking back on this section, the emergent question now is (RQ 1a) what kind of technology appropriation patterns exist, and (RQ 1b) to what extent audiovisual consumption in these patterns is explained by motivation, as opposed to habit.

\section{The social construction of technology}

The tenets of niche theory draw upon the assumption of reason and intention. The audience is seen as deliberately choosing the best possible and logical option. Still, we need to 
acknowledge social interaction theories that view the choice for a specific medium as the product of a social process (Watson-Manheim \& Bélanger, 2007). This is closely tied to the notion of social shaping, in which, as opposed to a deterministic point of view, technology is seen as a flexible social construction that is the consequence of action and specific choices in a social context. As such, it serves as a counterweight for pure diffusionism, seeing technology as neutral and independent of social interaction (Lievrouw, 2006). Livingstone concretizes: 'the accounting practices through which people understand and explain the role of domestic technologies in their lives reflect their gender relations and family dynamics. Talk about the television or the telephone, for example, is imbued with notions of who lets who use what, of moral judgments of other's activities, of the expression of needs and desires, of justifications and conflict, of separateness and mutuality' (Livingstone, 1992, p. 113). Hence, technologies are inherently meaningfully constructed. Drawing upon the literature on domestication theory (Silverstone \& Haddon, 1996), we must note that technology is appointed a necessary substrate for mediation of meaningful media texts to take place.

Technology meanings are actively negotiated before and during appropriation, in which they are given both a physical and a symbolic space, respectively in the physical domestic sphere and the household's dominant routines (Silverstone \& Haddon, 1996). This process is both implicit and explicit: as such it does not only assume individual ratio, but places it in the larger spectrum of social constraints, and its routines. The domestication perspective specifically gained prominence due to the stark increase in the number of technologies in the home, in the 1980-1990s, whereas before, the focus was uniquely directed at media texts, and their interpretation (Haddon, 2007). This evolution has not ceased to persist, and consequently, it is ever important to keep interest in the physical dimension of technology appropriation in the context of everyday media consumption, especially because the opportunities they enable persist to expand (Quandt \& von Pape, 2010). 
As argued, negotiation is inherently part of the construction. People do not necessarily accept the meanings that are originally tied to an innovation: they can be accepted, rejected, or (re)negotiated so they would fit the households' needs, beliefs, and former practices. We already touched upon the fact that although our houses are packed with technologies that afford the playback of audiovisual materials, this opportunity is seldom used (Courtois, et al., 2012). This means that some embrace the possibilities offered by these technologies, while others do not. But why is that so? In theory, many devices afford the same practices, but it is very unlikely that this is effectively the case. In fact, it is not because a technology has the capability of allowing a certain behaviour that this capability is identified and used as such. This links with the concept of perceived affordances (Norman, 2002), which refers to 'the perceived and actual properties of the thing, primarily those fundamental properties that determine just how the thing could possibly be used' (p. 9). That is what people see, not what the object is inherently capable of. Meaning can only exist when users identify an affordance. More specifically, people devise a mental model of objects, sketching the flow of how and for what to use objects, including various physical, semantic, cultural and logical constraints. When talking about mental models, it is only a small step towards schema theory (Whitney, Neil, \& Paul, 2001). At the core of this perspective, rooted in social cognitive psychology, is the concept of schema. Schemas are considered as organized collections of knowledge on a stimulus or a category of stimuli (objects, events, people, relationships). They are abstract structures of meaning, considered to be the building blocks of cognition. New information is fit into relations with others, in organized patterns, and remembered as such (Casson, 1983). Schemas function as an intermediary between stimulus and response and as such became a crucial notion in the cognitive revolution in psychology (Whitney, et al., 2001).

Schemas have multiple characteristics (Beals, 1998; Vonk, 1999; Whitney, et al., 2001). First of all, they have a domain; a specific topic and they also contain prototypical 
representations. Relations within schemas are logical, spatial or sequential in time and are based upon similarity and covariance. Among a variety of effects of schema, including means of information processing, schemas also hold the potential to activate behaviour, including automated behaviours. The latter is of importance to develop a deepening understanding of the results on the first research question. It is in important for us to gain insight in what people's cognitive schemas of audiovisual technologies look like, and most important: what affordances matter in the households' day-to-day realm, and which ones do not; What technologies provide these affordances, and again, which ones do not? These sub-questions fit our second, general research question. That is how to understand why differential repertoires of technologies are appropriated.

\section{METHODOLOGY}

\section{A research funnel}

In order to answer our two multi-faceted research questions, we implemented an integrated funnel approach. In a first phase, we devised a large-scale paper \& pencil survey with operational measures of habit strength and expected outcomes, the latter covering the aspect of motivation. Moreover, as will be discussed in the next section, we included a set of items inquiring what technologies are used to consume audiovisual content, in order to compile technology repertoires, using latent class analysis (Vermunt \& Magidson, 2006) First of all, these patterns allowed a multi-sample analysis of a model regressing consumption frequency on habit strength and expected outcomes. Secondly, the classes were used to sensibly recruit participants for a follow-up phase, consisting of domestic interviews. Chosen on the basis of very high to even absolute membership probabilities, the interviewees are treated as representatives for their respective classes. In the interview, we tapped into how media technologies are made meaningful and how it allows the exercise of everyday media consumption routines. 
Still, we first need to explicit our operationalization of audiovisual media consumption in today's increasingly converging media landscape. As put in the introduction, multiple devices furnish the consumption of audiovisual texts through various channels, while situated in a diversity of environments. Hence, we subscribe to an earlier empirically grounded recommendation for an agnostic approach towards media consumption (Courtois, Verdegem, \& De Marez, In press), inciting to tap into the experience, independent of a specific type of device, content or socio-spatial context. However, this poses another problem concerning the differences in experience of for example quickly watching a short news clip on a laptop computer at a desk versus taking time and making yourself comfortable to watch a film or series on the very same device. We strongly believe it is a mistake to treat both viewing modes as chips from the same block. Therefore, based on literature on human-computer interaction (Ruy \& Wong, 2007; Tsekleves, Whitham, Kondo, \& Hill, 2011), we heuristically distinguish between a haphazard lean forward viewing style and a much more dedicated lean back viewing style. In the survey questionnaire, both viewing styles were aptly introduced and familiarized by a textual situational sketch.

\section{Quantitative survey}

The paper and pencil questionnaire was administered on a large quota sample, targeting three age cohorts: young adulthood (18-30y), middle adulthood (31-50y) and late adulthood $(50 \mathrm{y}+)$, equally dispersed over gender. The data were gathered at the end of 2010 , in the context of a research methodology seminar at a large Belgian university. This led to a total number of 1,559 valid responses $\left(51 \%\right.$ male, $49 \%$ female; $\left.M_{\text {age }}=40.61, S D_{\text {age }}=16.79\right)$. The following paragraphs enumerate the applied measures.

Technology usage consists of six relatively common devices to consume audiovisual media: (a) television, (b) desktop computer, (c) laptop computer, (d) mobile media player, (e) mobile phone, and (f) portable DVD player. The respondents were asked to indicate how 
often they used these technologies to view audiovisual content of whatever kind. The ordinal response categories were (a) never, (b) less than weekly, (c) weekly, (d) every 2-3 days and (e) at least once a day. Tablets and netbooks were also included, but as their adoption rates were considerably low $(<5 \%)$, they were not included in the analysis.

Content consumption comprised of ten items measuring the frequency in which popular content genres are consumed, regardless of what device: (a) news casts, (b) current affairs, (c) documentaries, (d) soaps/series, (e) human interest, (f) films, (g) sports, (h) reality shows, (i) shows/game shows, (j) online clips. All categories were aptly illustrated by popular examples. The response categories were (a) never, (b) less than weekly, (c) weekly, (d) every 2-3 days, (e) once a day and (f) more than once a day.

The measures below were gathered for lean back viewing as well as lean forward viewing. The constructs' means, standard deviations and measures of internal consistency are summarized in Table 1.

Habit strength was assessed by Verplanken and Orbell's Self-Report Index of Habit Strength (2006). In line with current applications, items concerning past behavioural frequency were omitted (Verplanken, 2006). The ten remaining items were rated on a sevenpoint Likert scale ranging from 'totally disagree' to 'totally agree'.

Expected outcomes were measured by twelve items drawn from previous research (LaRose \& Eastin, 2004; Peters, Rickes, Jöckel, Von Criegern, \& Van Deursen, 2006). The original items were slightly adapted to fit audiovisual consumption. The four most recurrent expected outcomes that match $U \& G$ research on television were retained (LaRose, et al., 2001). Hence, novel, social, activity and self-reactive outcomes were assessed with sevenpoint Likert scales, ranging from 'very unlikely' to 'very likely' (Items are printed in the Appendix section). 
Consumption frequency was measured by inquiring the hours and minutes spent on viewing moving images one and two days before the survey administration. This measure's metric was eventually converted to minutes.

$$
<\text { Insert Table } 1>
$$

\section{Qualitative follow-up}

The second research question is oriented towards an in-depth understanding of the construction of audiovisual media technologies. For this purpose, a qualitative domestic research strand was designed. A number of nineteen informants were interviewed in their domestic environments ( 7 males and 9 females, aged 17 to 58). Each interviewee served as a typical case for one of the technology appropriation patterns, sketched later on.

The interview comprised several topics. Initially, the participant was requested to talk about a day in his or her everyday life, as a means to get to know the informant. In a second phase, photo-elicited cue cards with audiovisual technologies were presented. The interviewer would ask which technologies are present in the home, and which ones are used for what purpose. In a subsequent phase, the attention shifted to audiovisual media consumption. This activity was framed within everyday routines, and later within a technological repertoire, as discussed in the second phase. Next, a Q sorting task was presented (den Boer, Bouwman, Frissen, \& Houben, 1999; McKeown \& Thomas, 1988). A number of sixteen items were presented to the informant, asking to sort these on a pre-defined, normally distributed grid with seven positions, ranging from 'does not play a role' to 'plays a role'. The idea of a Q-sort is to incite participants to reflect upon the attributes presented on the cards, and to make explicit what they think matters, and what does not. More specifically, the participants were asked what attributes are important for them in an audiovisual technology, and which ones are not. The attributes, making up the Q-concourse, reflect affordances and were obtained from literature on adoption determinants (De Marez, Vyncke, Berte, Schuurman, \& De Moor, 
2007), supplemented with items based on the idea of a triple articulation (when, where, what, with whom). The items are enumerated in the table below.

$<$ Insert Table $2>$

During the Q-sorting task, the participants were invited to think aloud, so it becomes clear why a specific attribute is considered important, and how it is interpreted within the routine of audiovisual media consumption. Informants can dynamically alter the sorting patterns during the task until they reach a final solution they are comfortable with. The next and final task consists of going over the items one by one, and asking what technologies fit the attribute the best. As such, insight is gathered in what technologies fit the needs and expectations of the participants the best. Favoured characteristics are made explicit for what concerns their everyday use of audiovisual media technologies.

The analysis of the interview data started with the Q-analysis. A data matrix was composed with participants as variables, and items as cases. The cells are filled with the number associated to the position on the Q-grid (i.e. -3 to 3; Table 3). In a subsequent phase, a technique of data reduction (i.e. principal component analysis with an orthogonal rotation) is used to generate a simple structure of the data. This is discussed at length in the results section. Nevertheless, what we end up with is a set of components representing participants with very similar opinions on what matters in an audiovisual technology. These quantitatively derived patterns of attitudes are then used to guide the further qualitative analysis of the rest of the interview narrative. In contrast to a 'purely qualitative' analysis, Q-methodology helps the researcher substantially in finding data-driven patterns in data. Of course these patterns itself are interesting, but in itself they are not worth that much. The advantage is maximized when they are used to inform further analysis, searching the interview data for elements that allow understanding the derived position components. In this case, the components were explicitly crossed with the role of audiovisual technologies in daily life, the technologies that 
are appropriated, audiovisual media consumption routines, people's backgrounds and the specific opinions on attributes that matter most for the component at hand. This analysis comprised actively seeking cross-patterns, using component membership as case attribute.

$<$ Insert Table $3>$

\section{RESULTS}

\section{Patterns of technology appropriation}

In order to identify patterns in technology usage (RQ 1a), a latent class analysis was performed on the six inquired technologies. Latent class analysis (or latent cluster analysis) is a multivariate technique used to detect groups of respondents that share a similar pattern, while these groups differ as much as possible. Usually, in the analysis, the number of classes is steadily increased until a well-fitting model is found. In this case, this was a three-class model $\left(L^{2}(1481)=1552.24, p=.10\right)$. The response probabilities per class, depicted in Figure 1, indicate that the first class predominantly exists of status quo viewers, whereas there are rather small chances of frequently using a computer to view content. A different situation is noticed within the second class, which is made up by extension viewers who combine various technologies. Although television remains dominant, they also frequently employ computers and mobile phones. Finally, the third class is made up by substitution viewers, displaying the relatively highest chances of using a laptop on a daily basis for audiovisual consumption. These three distinct data-driven groups of respondents are further analysed as three different samples, and they will equally serve as a recruitment base in the qualitative follow-up study. $<$ Insert Figure 1 >

\section{The habit-goal interface}

In order to answer the second half of the first research question (RQ 1b), a structural equation model was specified for each viewing mode: lean back and lean forward. In these models, consumption frequency is used as a dependent variable, while expected outcomes and 
habit strength serve as independent variables. The analyses were ran on all three subsamples (status quo, extension and substitution), reaching an overall satisfactory goodness-of-fit of the lean back $\left(\chi^{2}(56)=255.12, \mathrm{TLI}=.91, \mathrm{CFI}=.92, \mathrm{RMSEA}=.05\right)$ and lean forward constrained measurement models $\left(\chi^{2}(56)=142.80, \mathrm{TLI}=.96, \mathrm{CFI}=.97, \mathrm{RMSEA}=.03\right)$. In a subsequent phase, both paths leading to consumption frequency ( $\mathrm{A}$ and $\mathrm{B}$ in figure 2 ) were constrained to equality in order to identify the strongest explanatory factor. In other words, we compare per technology appropriation pattern and viewing type whether a seeming difference in the unstandardized path coefficients A and B reflects a significant difference. If the $\Delta \chi^{2}$ proves to be significant at $p<.05$-level, we can conclude the paths differ in magnitude. Otherwise, we cannot draw such a conclusion and most treat them as equal in size. $<$ Insert Figure 2 >

Table 4 summarizes the analyses' results. The estimates in the table are unstandardized, meaning that an increase of one unit in the independent variable (on a seven-point metric) is associated with a change of $\mathrm{B}$ units in the dependent variable (viewing time in minutes). For example, a one-unit increase in expected outcomes scale in the first class is generally associated with an increased lean back viewing time (i.e. 16.40 minutes). Concerning lean back viewing, we notice that habit strength is generally a strong explanatory variable, whereas expected outcomes only yield significance for the status quo and substitution patterns. Moreover, it appears that for these two patterns, there is no difference in explanatory strength between habit and expected outcomes. In other words, both intentional and non-intentional factors yield equally strong predictions. For lean forward viewing, habit strength again proves to be an overall significant predictor, whereas expected outcomes only explain consumption frequency in the substitution pattern, of which we know the members are strongly tied to their laptop devices. 
These results are at least interesting when put in the outlined theoretical perspective. Whereas the theory of the niche explicitly draws upon intentional factors, neglecting the habit construct, it is this concept's operational measure that is a consistently strong predictor, whereas motivational factors are less important. When we take a closer look into the patterns, it is striking that the pattern in which various devices are placed next to each other, only habit is of importance. This suggests that these respondents engage with a variety of technologies, to furnish a ubiquitous consumption pattern. In the patterns that are more focused on a specific technology (either television, or the laptop), factors reflecting a deliberate choice do matter. This is at least the case for lean back viewing, while it only holds up for the substitution pattern in case of lean forward viewing. This is hardly surprising as the laptop is a device that commonly affords both viewing modes.

\section{A detailed map: Q-analysis}

As outlined in the introduction, the aim is to gain an understanding of the attributes that make a technology suitable for audiovisual media consumption. The Q-analysis devised to generate this insight is based upon a sixteen-item concourse. A principal component analysis with orthogonal varimax rotation on the Q-matrix produces a six-component solution, using the eigenvalue-over-one criterion. That is, a component needs to explain more variance in the initial variable pool than they add. Principal component analysis is a technique used for data reduction, commonly used in Q-analysis. The idea is that variables are reduced to components that independently explain as much as possible the variance in the original variables. The components consist of participants who share a very similar stance towards what attributes they feel are crucial in an audiovisual media technology. In other words, highly correlated participants are clustered in these components. The six discovered components jointly explain 82 per cent of variance in the initial item pool. 
After having devised a suitable model, we interpret the relations between participants and the derived components. In order to talk about a simple structure, it is imperative that participants are highly related to one component, while generally unrelated to others. This is expressed by the component loadings, which of course need to be significant in size. The conventional cut off for loadings with a $p<.05$ equals 1.96 multiplied with one divided by the square root of the number of items in the concourse (den Boer, et al., 1999). Consequently, the cut off amounts to .49. Table 5 summarizes all participants, their significant component loadings, and the variance explained by these components and their eigenvalues. The table reveals significant primary loadings for all participants. However, two negative loadings are present. This indicates that these participants have orthogonal opinions. In other words, they tend to contradict the general opinion within the component. Also, two participants display significant secondary component loadings, implying that they simultaneously tend towards two components.

\section{$<$ Insert Table $5>$}

Next, the question remains what these components represent. In order to get a hold of what participants in a component find important, regression factor scores are computed per component. These rank figures indicate the importance the 'average participant' in a component attributes to a specific concourse item. The higher the factor score of an item, the more important the item is for the participants reflected by the component. Table 6 summarizes the factor score ranking per component. As such it immediately becomes clear what the participants making up the component look for in an audiovisual technology, and what they find irrelevant. In the following paragraphs we thoroughly discuss each pattern, and add thick descriptions that were obtained through interviewer-participant interaction during the Q-sort and the rest of the interview.

$$
<\text { Insert Table } 6>
$$




\section{Affordable Sustainability}

Five participants make up the first component. However, Kris displays a negative component loading, so we decided exclude him from further analysis of the pattern. What we encounter is a group of people that has a strong tendency to favour an easy-to-use device that is ready for future developments, maximizing its value for money. In practice, this appears to be the television set in the living room that is used after a long workday, for instance to watch the news. This explains the dominant presence of people from the status quo pattern in this component. However, Mark, a single blue-collar worker who represents the substitution pattern, claims he practically traded his laptop for his television set, which is only used when he has visitors over:

Interviewer: You claim to have watched quite some television in the past, but now you use your laptop. How did that evolve?

Mark: I was already used to watching DVD's because I didn't want the constant advertising breaks of 10-15 minutes, they got on my nerves. So even before the laptop I watched DVD's. Then, I bought one with a DVD player, and quite a good screen. So it replaces my television. Anyway, broadcast television has too much advertisement on it.

Interviewer: You use the word 'replace', did it changed your viewing?

Mark: Yes, indeed. The laptop replaced the television, for all I concern the television may disappear.

Constraining audiovisual consumption to a preferred device is common practice for this pattern. Still, this does not mean that they are blind for technological innovation. Paul for 
instance was an early adopter of the iPhone and iPad, although not finding them fit for audiovisual consumption. Two other, middle-aged female participants in the component, Bernadette and Herlinde, are more modestly equipped at home. This does not prevent them from developing clear opinions on technological innovations, and what they mean to them. Herlinde actively tries to keep the use of media technologies tied to strict minimum. When we asked her how she thinks of new technologies, she does respond quite enthusiastically:

Herlinde: I think it is interesting to see, but not because I want to use it myself. You know, it struck me recently, that when we were flying back home by airplane, for six hours, that people are continuously working on their tablets. Then I think: I don't need that. I feel no urge, I'm not going to play games and such for six hours. I'm going to look around and bore myself some other way. I have no need to fill it with images. It's so stressing, I don't think it's relaxing.

The devices Bernadette and Herlinde use, are all neatly fit into compartments. Their television is for sporadic audiovisual consumption, their mobile phone for texting and voice calls, and their computer is a device for work. All of them have been around for a considerable amount of time.

\section{Autonomous Exploration}

The second component consists of attributes oriented towards the ability to consume at will, wherever and whenever preferred. Moreover, the issue of being able to independently seek new content is prominent. Four of our participants share significant and positive primary loadings. A further analysis of the interviews pointed out that three of them share some remarkable consistencies. Leen, Michael and Iris are all young adults in white-collar jobs, living in media-rich environments 
For example, Leen uses her laptop for her job, carrying it with her all the time. She shares a home with her boyfriend, his parents, his brothers, and one of those brothers' girlfriend. Although she has a private space there, the family shares many activities, including watching television. Her home is saturated with media technologies: five televisions, two iPads, and various PC's. Audiovisual content is prominently present in Leen's daily routines, it is a crucial aspect of her leisure time, especially at night when she watches broadcast television, or pops in a DVD. Furthermore, she claims visiting video-sharing sites like YouTube to watch short video clips. Moreover, there is a digital video subscription with a settop box in the living room, as well as in private spaces such as her own bedroom.

Like Leen, Iris consults multiple channels to get content: broadcast stream, video-ondemand through interactive digital television and online streaming through the Web. They do not engage in downloading materials. Both claim they do not really know how and thus lack the skills, although they are familiar with people who do. However, Michael is quite competent in looking for online content, and downloading it to his computer, which makes his consumption utmost deliberate, following a strategic schema:

Interviewer: You mostly watch films and series, how do you get them? Michael: I download them. Interviewer: How do you guide your choices? Michael: I have a website, IMDB, I check if a film is good or not, that what I base it on.

Michael has a range of devices he uses quite intensively. He, like the previously discussed participants, display intensive patterns of 'cross-media' jumping (Hess et al., 2011). That is, skipping form one (related) medium to another in the proverbial blink of an eye. 
During commuting, on the train, he watches series on his iPod, next to surfing the Internet. At home, his girlfriend has the tendency to put on the television as soon as she gets home, rendering the device ever present, especially when they watch it together at night. However, when Michael feels like watching something specific, he goes on the Web with his laptop to download targeted content. He then hooks up his device to the television screen, as a go inbetween:

Interviewer: Why did you get a television set?

Michael: I think it's the classic story: everyone has a television set. Although, for me, it's not really necessary. I could easily do without, but my girlfriend couldn't. For me TV is something that displays images, just a large screen.

Further in the interview he considers people who stick to the television screen as 'analphabets in this evolution', explaining why the extension pattern is strongly represented in this component. Karin however, only uses television, but she has multiple devices and a digital connection. Although she is satisfied with linear broadcast, and zapping through it, she does have a digital connection enabling her to access a large collection of self-recorded broadcasts. She, as well as other interactive digital television viewers in our study embrace the time-shifted opportunities offered by interactive digital television, breaking out of structural constraints that once limited television viewers (Van den Broeck, Bauwens, \& Pierson, 2011). This would imply a lesser influence of structural factors in terms of audience availability (being able to watch) and access (device and channel availability), which used to be significant explanatory factors in audience exposure (Cooper \& Tang, 2009), in favour of motivation and routine. Still, the opposition in Michael and Karin's positions is striking. Michael considers television viewers as 'analphabets', considering his 'literate' style of seeking 
content as progressive. On the other hand Karin claims that her multiple (digital) screens provide her with all the autonomy she needs. Both, in their own way, empower themselves to go beyond, or at least manipulate the structural factors that were omnipresent in a singularly linear broadcasting environment.

\section{Affordable Quality}

The third component displays a strong sensitivity to getting a reliable and high quality experience at reasonable pricing. Also important are compatibility and the ability to use a device in a comfortable setting and hook it up to other devices (i.e. the television screen, as there is a contingency with the status quo pattern). However, there is no apparent need for social viewing. Likewise, the combination with other activities as well as being able to independently seek content through the device itself is deemed irrelevant.

Philip lives together with his wife and occasionally his son, who has a student room during the week. Because of health issues he is permanently at home. Nevertheless, he actively pursues a well-filled day by engaging with media, do administration, go out to volunteer at a high school library and visit friends. He is quite tech savvy as he has always been working with technologies, keeping himself up-to-date. Nevertheless, besides an occasional online clip, or trying online VOD, he finds little advantage going beyond his television screen because it offers the best quality, while experiencing no constraints that threaten his perceived autonomy to watch what he wants: he is home a lot, and there is no disagreement about what to watch. Philip emphasizes the television set as the most suitable device:

Philip: I can't image a situation in which I would not use the television. I know that my daughter, and my son too, that they watch DVD's on their laptop. That's just not for me. I mean, you have a television, with a hard drive, a DVD player, a Playstation, a 
Blue Ray player. Why would you want to watch a film of series on your laptop? Except for when you're in a space without a television. My wife does that, when she's working out in her room, there's no TV there. There she has an old laptop to watch a DVD, but in my case, such situations don't occur.

Participant David steadily progressed from broadcast TV to content he selects by getting DVD's or downloading files. Like in Philip's case, the TV is seen as a central hub: 'My Playstation 3 is hooked up to my TV, that's a major pro because for me, it's the gateway to multimedia, for an active user. 'In other words: it is not the viewing device that allows for seeking and harvesting content, this is done by other, external means. Elke, who works as a counsellor in secondary education, has a similar story. She too lives at home with her parents and has a private set she uses for linear broadcast, VOD, DVD playback and downloaded materials through a media centre (a so-called Moviebox). Like David, she combines different external channels in order to see what she wants beyond the linear stream. What we notice here, namely the considerable occurrence of integrative media consumption practices was also found in earlier research (Hess et al., 2012).

\section{Comfortable reliability}

The fourth component favours a reliably functioning device that is constantly available, and is located in a comfortable setting, while allowing for social viewing. Issues considering aid in finding and selecting specific content are not apparent, while there is no specific consideration of device design and pricing. In terms of technology, this comfortable setting appears quite diverse. The only contingency is the dominance of a large television screen. Maggie and Saskia both have one rather old tube television, although Saskia switched to a digital connection because of a triple play promotion campaign by telecom operator 
Telenet. Both women have busy jobs and families with children, who occupy the set in the early evening. Afterwards, Saskia tends to join them, whereas Maggie usually waits until she is on her own to watch out of own interest. Although Maggie admits to sometimes browsing the Web to find video materials for her lectures, she mentions considering this strictly business, whereas watching television at night is a moment of relaxation, which explains her desire for a comfortable context, watching an easy, intuitive device. Maggie does not have a digital connection, although she fully acknowledges the advantages to skip ads - even though she is a professor in marketing, she tends to get annoyed with long-winded, low-quality advertisement - and to be able to engage in time-shifted viewing, so the television schedule would adapt to her schedule, and not the other way round. This is the reason why she considers to switch. Saskia already switched. She too is a routine viewer, although she equally claims not to be drawn to the television that much. When she is working on a task, she does not feel inclined to interrupt. When asked how she looks upon recent developments, she admits she tends to let the evolution pass:

Saskia: Yeah, I think in that respect [sticking to the television screen] we're quite traditional. My husband isn't too much a freak with those things too. We're traditional in the respect that we've always been modest viewers. I can imagine that when you watch a lot, that you feel much more like jumping the bandwagon. But the fact that we don't watch that much makes that we don't feel much of an urge to go along with this evolution.

Saskia is very satisfied with the technology she has right now, considering its reliability as a major advantage. In her opinion a television is easy to operate, and always works unless there is a structural problem with the cable company. Still, the dependence on 
broadcast television is not a prerequisite to belong to this component. Student Sharon, who has a significant positive secondary loading on this component (next to having a negative primary loading on the fifth component), does not own a television. Instead, she shares a media centre (i.e. a Boxeebox) with her boyfriend that is connected to a large television display; she nonetheless does not consider a television per se. Her boyfriend is responsible for gathering content, that ranges from downloads to DVD's. Sharon is quite pleased with the easy to use the device, and with the central function it fulfils. She can imagine using it for a long time, as it replaces traditional broadcast television.

\section{Routine quality}

The fifth component considers it of the utmost importance that a device fits the daily routines, delivering high quality sound and images in a social setting, while also affording more than one relevant function. Its readiness for the future, design and aspects of mobility are considered irrelevant.

There is one positive component loading, represented by Fauve, a 17-year old girl who goes to high school, while living with her mother and sister. She is quite constrained when it comes to electronic devices: she has the family desktop at her disposal, and sometimes she can use her sister's laptop, but not for considerable audiovisual content consumption, apart from some YouTube music videos every once and a while. Television however takes a substantial part of her life. Before the other family members, she wakes up at a quarter to six in the morning, a moment at which she watches some television. At night, after dinner, she continues until nine or ten. Also in the weekends, she tends to watch films and series she finds on the video-on-demand catalogue, or which she recorded earlier on with the PVR. It is rather obvious that Fauve's leisure routines are quite centred around the screen.

Being constrained from other means of consumption is only a part of the explanation why Fauve likes the television set so much. Fauve seems quite tied to the television as it offers 
enough variation (i.e. the VOD catalogue is sufficiently diverse). Moreover, she has no issues concerning rules and ownership, claiming that she 'wins' family disputes on what to watch.

Still, Fauve's orientation to watching audiovisual materials is predominantly a social one. She is very much drawn to watching together, and she even argues she finds the evolution of individualization an unpleasant one:

Interviewer: Would it be something for you, to get rid of the television and watch on other devices?

Fauve: No, I think that a television is still something you need to have at home, just a general thing that everybody has, otherwise you're all watching separately, that just isn't fun.

Interviewer: Who do you think would do that?

Fauve: Euh, people of my age who watch a laptop, they're at their rooms watching films. I have a friend who only watches DVD's upstairs, in his room

Fauve: I do watch other devices, but it's mostly the television because that's the best and the most pleasant to watch, also because it's together with your family. Interview: How do you end up watching other devices?

Fauve: Yeah, when I'm not at home, and you're not at someone else's. If you have an iPod or a portable DVD player, then it's easy to watch those. Or a mobile phone... It's automatic, just because you can, you do.

\section{Easy Exploration}

The sixth component is characterized by a desire to be able to search for materials by means of an easily accessible and reliable device, yet delivering sound and images with 
excellent image and sound quality. Fitting well in daily routines is not much of a concern, as well as compatibility with other devices or activities.

The participants in this component are quite diverse: two middle-aged women, and college student Bram. Bram has a student room, while on the weekends he lives with his parents. Although there is a television set at home, he claims not to use it that often, as his laptop is much more important to him. Born in 1992, he reflects on being brought up with the Internet, and watching audiovisual materials on his computer ever since he got a laptop, at the age of 16. At that point, he started watching DVD's on the device, and downloading files and streams, advised by his friends (i.e. in conversation or on social media). In that spirit, it is quite logic for Bram to use his laptop, as it affords him the means to look for content, which in the four years of experience he gathered, do not pose any difficulties. Broadcast television however, leaves him unsatisfied:

Interviewer: Are you regular television viewers, at home?

Bram: No, not at all... my sister a bit more than I do, but it doesn't appeal to me. I use my laptop to watch films, when I'm not pleased with what's on. On a television, you can't choose what you want to watch. I mean, we have digital television, but we don't use it that often, we don't rent films. I think it's much more fun when you can choose what you watch.

Interviewer: Is there too little choice with digital television?

Bram: I can't record programs when I'm in Ghent [where he studies], so I have to count on my parents to record during the week. I don't think much of digital television; perhaps I should rent a movie. But when I watch TV, it's for the news, or a series, sometimes. 
This is quite the other way round with both other participants. They do use the Internet to watch short clips. For instance, searching the Web - also for video materials - has become one of Martine's favoured activities she deliberately sits down for, saving her a trip to the library. Still, her consumption is much more oriented towards the television. Also in that case, she is quite selective in what and when she watches. As soon as her interest fades, the device is switched off. Since she has interactive digital television, she claims to be even more selective. Also in Griet's case, being able to select content is of major importance. She often watches films from the video-on-demand catalogue on her television. Although she would consider using her Apple iMac computer to watch things, she chooses not to because it is located at a desk, which is not that comfortable to lean back at. For her, the television is a much more logical option. Nevertheless, Martine argues that any situation can be made comfortable, so even a laptop can afford a pleasant experience.

\section{DISCUSSION}

In this paper, we introduced the issue of diversity in audiovisual technology use. Three major patterns surfaced in a diverse quota sample: maintaining the status quo by sticking to television, expanding this practice by means of using multiple devices, and relatively displacing the television by a laptop device. Caught in the context of using multiple competing media, we reprised niche theory, positing that media choices are based on explicit gratifications. However, in finding a response to our first research question, in line with previous research, we have noticed that the habit construct is a persistent predictor of audiovisual media consumption, regardless of the devices used. Only when the pattern of technological substrate tends to be focused on a single device, motivation (i.e. expected outcomes) comes into play. This suggests that constraining oneself to a single screen is associated with making more deliberate choices, while using multiple devices enables to 
exercise a strong habit. This supports the routine ubiquity assumption that is apparent in recent literature on the conceptualization of media consumption; e.g. media life (Deuze, 2011)

Still, we cannot make any claims on causality: does a strong habit evoke the appropriation of more devices, or does having more devices support building a strong habit? Longitudinal research is needed to investigate this matter. Still, based on the gap between adoption and use diffusion, we hypothesize the former. That is to say, we presume that broad technology repertoires are able to support a strong habit, but do not necessarily evoke building one. This consequently causes reflection on niche theory as applied to the convergent technology dimension. Although intuitively valid, it is clear that it needs to adapt to the finding that habits may be a driving force to appropriate devices, rather than prospective gratification. It fundamentally threatens the assumption of conscious deliberation, indicating it as a too narrow view.

In an attempt to elicit cognitive schemas on the necessary characteristics of audiovisual media technologies, we encountered a substantial diversity in our small follow-up sample. It immediately shows that there is no strict contingency between the technology patterns and the derived Q-components. In each case, there is a mixture of patterns. This confirms that the construction of audiovisual technology is inherently subjective, and depends on the appropriators experience, insight, and of course social environment. Again, we need to reflect upon niche theory, considering it as a framework to approach technology choices. Due to technological convergence, devices' affordances are increasingly overlapping. Could it be that niches are disappearing, and that the notion of a niche is gliding into oblivion? In its current application the answer is probably yes. Still, in our research we have found that differences in preferred affordances exist. However, the devices that are used to deliver those are rather diverse, and hence, it is almost impossible to infer why a specific set of technologies are used. That is why we propose to detach niches from technologies, and media 
in general, and revert to what is done with these technologies: how they are used, in what circumstances, and what kind of content is consumed with them. A niche study nowadays should abstain from linear claims on the gratifications of specific media, or media technologies. In this matter, we feel that Hasebrink and Hölig's (2011) idea of communication modes could be a substantial part of a solution. Communication modes comprise how users define what they are doing with media within the boundaries of the communication service, reflecting the objective potential of the service at hand. Due to its level of abstraction, it is not necessarily tied to a specific technology, what is the major advantage of it. What we suggest is that instead of inquiring the gratifications (and also habit, to be consistent with our previous suggestion) of a specific technology (or media in extenso), it could be more productive to ask about communication modes that are to be derived through a qualitative pilot. To give a quick, tangible sense of what a communication mode might be, Hasebrink and Hölig (2011) proposed a number of heuristic examples related to 'television': i.e. watching a linear broadcast, the home cinema experience, surfing through channels, time-shifted viewing, ondemand viewing, networked communication (i.e. forward content through social media - or re-mediation). Put differently: the focal point should be what is the reward of a communication mode, and then focus on how we get there.

That said, let us reprise the profiles derived from the Q-analysis, which give us a clear view on what people primarily want to do with audiovisual technologies. These indicate that, relative to exact instances of appropriated technology, different accents are put into the expectations of technologies. What shows, is the importance of ease and comfort on the one hand, and the related ability for autonomy on the other. A constant is that our participants are increasingly seeking to mold their audiovisual consumption into their daily activities, rather than the other way round. Still, there is quite some diversity in how this is accomplished. A proportion of participants is satisfied with being able to zap through existing linear program 
streams, whereas participants with a interactive digital television connection strongly rely in relatively easy operable time-shifted viewing and to some extent also video-on-demand (i.e. comfortable reliability and affordable sustainability). As such, control over what is watched, in what circumstances, is increasingly put with the viewer, rather than the broadcaster. Nevertheless, the younger participants tend to go some steps further. They gain even more control over their audiovisual consumption by going beyond the broadcast offer, or even institutionalized video-on-demand services, by downloading video materials or streaming them online, watching content on multiple devices, even mobile ones as to fit daily routines (i.e. autonomous exploration). Still, this does by no means renders the television screen irrelevant. On the contrary, this screen has the ability to function as a hub, connected to various devices that equally support large degrees of autonomy in terms of seeking content, and scheduling consumption according to fit daily activities (i.e. affordable quality and easy exploration). Moreover, the television screen is still a device that is commonly associated with a joint experience, so the social motivation is an equally important factor (i.e. routine quality).

What we need to keep in mind is that with the help of varying technologies, viewers have gained the power to disperse, and increasingly control their viewing behaviours as to fit daily practices, rather than other way round. This implies a decline in control of the broadcasting institutions over 'the audience', which complicates their imperative venture of maximizing and grasping this 'audience', that is, for better or for worse diffused into various sets of audiences. This requires alternative means of measurement and delivery, something broadcasters at the time are still struggling with.

Another issue is that the increased control of viewers is not unproblematic. By increasing the variation in technology appropriation, and the required acquisition of digital skills, not only on an operational level, but also on a strategic level, viewers are not dealt with 
equal resources to go beyond. Viewers lacking in skills might just be unable to embrace alternative channels, or, they could be pushed into another kind of dependent relation. For instance, during the interviews, we heard about depending on significant others to help and deliver content. This might be a new kind of dependency within the family environment, perhaps a new 'remote control' (Walker, 1996).

In conclusion, this research paper sheds light on the composition of repertoires of audiovisual technology, and provides insight in the substrate of the consumption behaviour they accommodate in terms of habit as opposed to motivation. We have found that both elements matter, which holds vast implications for niche theory, apart from the call to detach it from a specific media technology (and content the like). Moreover, we engaged in a multistrand research, further qualitative inquiring what people seek in audiovisual technologies, and how they implement these in their daily viewing routines. We noticed how the orientations towards audiovisual technologies are only mildly contingent with the technology patterns. This causes us to doubt the very substance of niches in the audiovisual. Of course those still exist, but we do think their delineation is weakening because it appears that similar positions of what to expect from audiovisual media technology, and how to handle them, are exemplified by people who draw upon different technologies. These technologies are capable of the same things, so their discriminating power is declining. We believe that in future applications of niche theory, gratifications and habits of communication modes should be taken into account, rather than the problematic term of media as such. And these should of course be differentially linked to technology, content and context; that is, per media consumer. Niche theory's core idea remains, but its applications should be updated to (novel) theoretical insights that match the evolving media environment.

\section{References}


Beals, D. E. (1998). Reappropriating Schema: Conceptions of Development From Barlett and Bakhtin. Mind, Culture, and Activity, 5(1), 3-24.

Casson, R. W. (1983). Schemata in cognitive anthropology. Annual review of Anthropology, $12,429-462$.

Cooper, R., \& Tang, T. (2009). Predicting Audience Exposure to Television in Today's Media Environment: An Empirical Integration of Active-Audience and Structural Theories. Journal of Broadcasting \& Electronic Media, 53(3), 400-418.

Courtois, C., D'heer, E., \& Schuurman, D. (2012). Technological convergence in audio-visual technologies. International Journal of Digital Television, 3(2), 187-196.

Courtois, C., Verdegem, P., \& De Marez, L. (In press). The Triple Articulation of Media Technologies in Audiovisual Consumption. Television \& New Media.

De Marez, L., Vyncke, P., Berte, K., Schuurman, D., \& De Moor, K. (2007). Adopter segments, adoption determinants and mobile marketing. Journal of Targeting, Measurement \& Analysis for Marketing, 16(1), 78-95.

den Boer, D. J., Bouwman, H., Frissen, V., \& Houben, M. (1999). Methodologie en statisiek voor communicatieonderzoek. Houten: Bohn Stafleu Van Loghum.

Deuze, M. (2011). Media Life. Media, Culture \& Society, 33(1), 137-148.

Dimmick, J. (2003). Media competition and coexistence: The theory of the niche. Mahwah, NJ: Lawrence Erlbaum.

Dimmick, J., Kline, S., \& Stafford, L. (2000). The Gratification Niches of Personal E-mail and the Telephone: Competition, Displacement, and Complementarity. Communication Research, 27(2), 227-248.

Haddon, L. (2007). Roger Silverstone's legacies: domestication. New Media \& Society, 9(1), 25-32. 
Hasebrink, U., \& Hölig, S. (2011). What is the TV audience? The audience's perspective. Paper presented at the Transforming Audiences, Transforming Societies COST Meeting.

Hess, J., Ley, B., Ogonowski, C., Wan, L. \& Wulf, V. (2011). Jumping between devices and services: Towards an integrated concept for social tv. Paper presented at the EuroITV 2011, Lisbon, Portugal.

Hess, J., Ley, B., Ogonowski, C., Reichling, T., Wan, L. \& Wulf, V. (2011). New Technology@Home: Impacts on Usage Behavior and Social Structures. Paper presented at EuroITV 2012, Berlin, Germany.

Jenkins, H. (2006). Convergence culture: Where old and new media collide. New York: NYU press.

LaRose, R. (2010). The Problem of Media Habits. Communication Theory, 20(2), 194-222.

LaRose, R., \& Eastin, M. (2004). A Social Cognitive Theory of Internet Uses and Gratifications: Toward a New Model of Media Attendance. Journal of Broadcasting \& Electronic Media, 48(3), 358-377.

LaRose, R., Mastro, D., \& Eastin, M. (2001). Understanding Internet Usage: A SocialCognitive Approach to Uses and Gratifications. Social Science Computer Review, 19(4), 395-413.

Li, S. C. S. (2001). New media and market competition: A niche analysis of television news, electronic news, and newspaper news in Taiwan. Journal of Broadcasting \& Electronic Media, 45(2), 259-276.

Lievrouw, L. (2006). New Media Design and Development: Diffusion of Innovations vs. Social Shaping of Technology. In L. Lievrouw \& S. Livingstone (Eds.), Handbook of New Media (pp. 246-265). London: Sage. 
Livingstone, S. (1992). The meaning of domestic technologies: A personal construct analysis of familial relations. In E. Hirsch \& R. Silverstone (Eds.), Consuming Technologies (pp. 113-130). London: Routledge.

McKeown, B., \& Thomas, D. (1988). Q Methodology. Newbury Park: Sage.

Murray, S. (2003). Media convergence's third wave. Convergence, 9(8), 8-18.

Norman, D. A. (2002). The design of everyday things. New York: Basic Books.

Peters, O., Rickes, M., Jöckel, S., Von Criegern, C., \& Van Deursen, A. (2006). Explaining and analyzing audiences: A social cognitive approach to selectivity and media use. Communications, 31(3), 279-308.

Quandt, T., \& von Pape, T. (2010). Living in the Mediatope: A Multimethod study on the evolution of media technologies in the domestic environment. The Infortmation Society, 26(5), 330-345.

Ramirez, A., Dimmick, J., Feaster, J., \& Lin, S. F. (2008). Revisiting Interpersonal Media Competition The Gratification Niches of Instant Messaging, E-Mail, and the Telephone. Communication Research, 35(4), 529-547.

Ruggiero, T. (2000). Uses and Gratifications Theory in the 21st Century. Mass Communication \& Society, 3(1), 3-37.

Ruy, H., \& Wong, A. (2007). Perceived usefulness and performance of human-to-human communcations on television. Computers in Human Behavior, 24(4), 1364-1384.

Shih, C.F., \& Venkatesh, A. (2004). Beyond Adoption: Development and Application of a Use-Diffusion Model. Journal of Marketin, 68(1), 59-72.

Silverstone, R., \& Haddon, L. (1996). Design and the domestication of information and communication technologies: technical change and everyday life. In R. Mansell \& R. Silverstone (Eds.), Communication by Design. Oxford: Oxford University Press. 
Smith, M. D. T. R. (2009). Competing with free: The impact of movie broadcasts on dvd sales and internet piracy. [Article]. MIS Quarterly, 33(2), 321-338.

Tsekleves, E., Whitham, R., Kondo, K., \& Hill, A. (2011). Entertainment Computing, 2(3), $151-161$

Van den Broeck, W., Bauwens, J., \& Pierson, J. (2011). The promises of iDTV: Between push marketing and consumer needs. Telematics and Informatics, 28(4), 230-238.

Vermunt, J. K., \& Magidson, J. (2006). Latent Class Analysis. from http://www.statisticalinnovations.com/articles/Latclass.pdf

Verplanken, B. (2006). Beyond Frequency: Habit as a Mental Construct. British Journal of Social Psychology, 45(3), 639-656.

Verplanken, B., \& Orbell, S. (2006). Reflections on Past Behavior: A Self-Report Index of Habit Strength. Journal of Applied Social Psychology, 33(6), 1313-1330.

Vonk, R. (1999). Cognitieve Sociale Psychologie: Psychologie van het dagelijks denken en doen. Utrecht: Lemma.

Walker, A. J. (1996). Couples watching television: Gender, power, and the remote control. Journal of Marriage and the Family, 58, 813-823.

Watson-Manheim, M. B., \& Bélanger, F. (2007). Communication Media Repertoires: Dealing with the Multiplicity of Media Choices. MIS Quarterly, 31(2), 267-293.

Whitney, P., Neil, J. S., \& Paul, B. B. (2001). Schemas, Frames, and Scripts in Cognitive Psychology International Encyclopedia of Social \& Behavioral Sciences (pp. 1352213526). Oxford: Pergamon. 


\section{APPENDIX}

Expected outcomes scale. Both viewing type measures demonstrate a satisfactory overall measurement model fit on three random subsamples. Incremental $\chi^{2}$-tests indicate invariant measurement weights, intercepts and structural covariances. All indicators are significant at $p<.001$.

\begin{tabular}{|c|c|c|}
\hline Construct & $\lambda$ Lean back & $\lambda$ Lean forward \\
\hline \multicolumn{3}{|l|}{ Activity } \\
\hline Amuse yourself & .82 & .87 \\
\hline Have a good time & .78 & .88 \\
\hline Feel uplifted & .69 & .80 \\
\hline \multicolumn{3}{|l|}{ Novel } \\
\hline Get track of important news & .88 & .91 \\
\hline Keep track of events & .86 & .86 \\
\hline Learn new things & .53 & .67 \\
\hline \multicolumn{3}{|l|}{ Self-reactive } \\
\hline Enjoy the moment & .78 & .81 \\
\hline Forget daily burdens & .56 & .65 \\
\hline Relax yourself & .54 & .58 \\
\hline \multicolumn{3}{|l|}{ Social } \\
\hline Strengthen your social ties & .81 & .82 \\
\hline Share an activity & .72 & .80 \\
\hline Feel part of a group & .81 & .83 \\
\hline $\begin{array}{l}\text { Model fit on three random subsamples: } N= \\
520,483,471\end{array}$ & $\begin{array}{l}\chi^{2}(144)=619.42 \\
\text { TLI }=.91 \\
\text { CFI }=.93 \\
\text { RMSEA }=.05\end{array}$ & $\begin{array}{l}\chi^{2}(144)=400.46 \\
\text { TLI }=.94, \\
\text { CFI }=.96, \\
\text { RMSEA }=.04\end{array}$ \\
\hline
\end{tabular}


Table 1. Measures means, standard deviations and Cronbach's $\alpha$.

\begin{tabular}{lllllll}
\hline Construct & \multicolumn{3}{l}{ Lean back viewing style } & \multicolumn{3}{c}{ Lean forward viewing style } \\
& $M$ & $S D$ & $\alpha$ & $M$ & $S D$ & $\alpha$ \\
\hline Expected outcomes & & & & & & \\
$\quad$ Social & 3.16 & 1.24 & .79 & 2.93 & 1.34 & .80 \\
Novel & 4.67 & 1.20 & .79 & 4.89 & 1.35 & .84 \\
Self-Reactive & 4.39 & 1.12 & .70 & 3.30 & 1.15 & .76 \\
$\quad$ Activity & 5.07 & 1.05 & .82 & 3.77 & 1.33 & .88 \\
Habit strength & 4.74 & 1.34 & .88 & 3.43 & 1.31 & .91 \\
Consumption frequency & 108.77 & 77.62 & $(r=.43)$ & 24.95 & 34.10 & $(r=.70)$ \\
\hline
\end{tabular}


Table 2. Sixteen item Q-concourse.

\section{Concourse attributes}

Easily fits my daily routines

Allows me to watch whenever I want

Allows me to use wherever I want

Allows me to use in a comfortable situation

Provides the opportunity to watch with who I want

Allows me several relevant functions

Easily combines with other devices

Allows me to search for new content
Functions in a reliable fashion

Is easy to use

Provides high quality sound and images

Allows me to combine with other activities

Has an attractive design

Gives me my money's worth

Helps me figuring out what to watch

Is a device ready for future developments 
Table 3. Fixed Q-grid with seven positions, presented to the participants.

Does not play a role

Plays a role

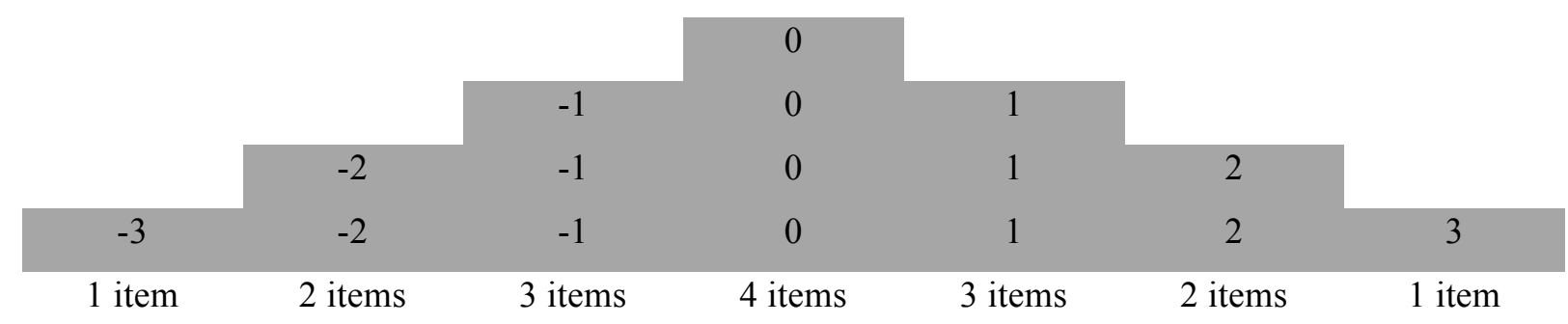


Table 4. Summary of the multi-group analysis of the media attendance model.

Parameter estimates when constraining measurement weights and intercepts to equality for all three classes. ${ }^{++}$Model nested within constrained measurement model. ${ }^{*} p<.05,{ }^{*} p<$ $.005, * * * p<.001$. When a unit is added in an independent variable (expected outcomes and/or habit strength), the dependent variable (i.e. attendance) increases with B minutes. For example, in the first class, an increase of one unit in expected outcomes generally brings about an increased lean back viewing time of 16.40 minutes.

\begin{tabular}{|c|c|c|c|c|c|c|}
\hline \multirow[t]{4}{*}{ Path specifications } & \multicolumn{6}{|c|}{ Parameter estimates $^{+}$} \\
\hline & \multicolumn{2}{|l|}{ Class 1: } & \multicolumn{2}{|l|}{ Class 2: } & \multirow{2}{*}{\multicolumn{2}{|c|}{$\begin{array}{l}\text { Class 3: } \\
\text { Substitution }\end{array}$}} \\
\hline & \multicolumn{2}{|l|}{ Status Quo } & \multicolumn{2}{|l|}{ Extension } & & \\
\hline & B & $S E$ & B & $S E$ & B & $S E$ \\
\hline \multicolumn{7}{|l|}{ Lean back viewing: } \\
\hline Path A: Expected & & & & & & \\
\hline outcomes $\rightarrow$ & $16.40 * * *$ & 3.29 & 4.69 & 3.89 & $18.32 * * *$ & 5.28 \\
\hline Attendance & & & & & & \\
\hline $\begin{array}{l}\text { Path B: Habit strength } \\
\rightarrow \text { Attendance }\end{array}$ & $19.67 * * *$ & 1.99 & $19.27 * * *$ & 2.03 & $11.46^{* * *}$ & 2.13 \\
\hline $\begin{array}{l}\text { Models with both paths } \\
\text { constrained to equality: }\end{array}$ & \multicolumn{2}{|l|}{$\Delta \chi^{2}=.60$} & \multicolumn{2}{|c|}{$\Delta \chi^{2}=9.07 *$} & \multicolumn{2}{|l|}{$\Delta \chi^{2}=1.35$} \\
\hline \multicolumn{7}{|l|}{ Lean forward viewing: } \\
\hline \multicolumn{7}{|l|}{ Path A: Expected } \\
\hline \multicolumn{7}{|l|}{ Attendance } \\
\hline $\begin{array}{l}\text { Path B: Habit strength } \\
\rightarrow \text { Attendance }\end{array}$ & $10.63 * * *$ & .82 & $15.06 * * *$ & 1.22 & $7.71 * * *$ & 1.01 \\
\hline $\begin{array}{l}\text { Models with both paths } \\
\text { constrained to equality: }\end{array}$ & \multicolumn{2}{|c|}{$\Delta \chi^{2}=44.81^{* * *}$} & \multicolumn{2}{|c|}{$\Delta \chi^{2}=35.55^{* * *}$} & \multicolumn{2}{|l|}{$\Delta \chi^{2}=.60$} \\
\hline
\end{tabular}


Table 5. Summary of participants, component loadings, and component $R^{2}$ and eigenvalues. $A$ component loading ranges from -1 to 1 and reflects the degree to which a single participant is in accordance with the pattern reflected by the component. For example, Mark strongly exemplifies the first pattern, or component.

\begin{tabular}{|c|c|c|c|c|c|c|}
\hline Participants & C1 & $\mathrm{C2}$ & C3 & $\mathrm{C4}$ & $\mathrm{C5}$ & C6 \\
\hline Mark (Substitution, 31, M) & .85 & & & & & \\
\hline Herlinde (Status Quo, 58, F) & .82 & & & & & \\
\hline Bernadette (Status Quo, 50, F) & .78 & & & & & \\
\hline Paul (Status Quo, 56, M) & .71 & & & & & \\
\hline Kris (Extension, 26, M) & -.55 & & & & & \\
\hline Iris (Extension, 38, F) & & .85 & & & & \\
\hline Karin (Status Quo, 49, F) & & .80 & & & & \\
\hline Leen (Extension, 26, F) & & .78 & & & & \\
\hline Michael (Extension, 24, M) & & .75 & & & & \\
\hline David (Status Quo, 25, M) & & & .86 & & & \\
\hline Elke (Status Quo, 26, F) & & & .83 & & & \\
\hline Philip (Status Quo, 48, M) & & & .80 & & & \\
\hline Maggie (Extension, 43, F) & & & & .89 & & \\
\hline Saskia (Status Quo, 41, F) & & & & .63 & & \\
\hline Fauve (Extension, 17, F) & & & & & .83 & \\
\hline Sharon (Extension, 23, F) & & & & .54 & -.62 & \\
\hline Martine (Extension, 55, F) & & & & & & .76 \\
\hline Griet (Status Quo, 50, F) & & & .59 & & & .70 \\
\hline Bram (Substitution, 21, M) & & & & & & .53 \\
\hline $\mathrm{R}^{2}$ & .19 & .16 & .15 & .12 & .10 & .09 \\
\hline Eigenvalue & 5.06 & 3.54 & 2.68 & 1.70 & 1.45 & 1.06 \\
\hline
\end{tabular}


Table 6. Factor score ranks per component. A high rank (1, 2, 3, etc.) means that the participants in the component consider the attribute very important in their ideal conception of an audiovisual screen technology, whereas low ranks $(16,15,14$, etc.) point to unimportance. The top and bottom three scores are specifically indicated.

\begin{tabular}{|c|c|c|c|c|c|c|}
\hline & $\begin{array}{c}\text { C1: } \\
\text { Affordable } \\
\text { Sustainability }\end{array}$ & $\begin{array}{c}\text { C2: } \\
\text { Autonomous } \\
\text { Exploration }\end{array}$ & $\begin{array}{c}\text { C3: } \\
\text { Affordable } \\
\text { Quality }\end{array}$ & $\begin{array}{c}\text { C4: } \\
\text { Comfortable } \\
\text { Reliability } \\
\end{array}$ & $\begin{array}{l}\text { C5: } \\
\text { Routine } \\
\text { Quality }\end{array}$ & $\begin{array}{c}\text { C6: } \\
\text { Easy } \\
\text { Exploration }\end{array}$ \\
\hline Easily fits my daily routines & 13 & 4 & 8 & 7 & 1 & 14 \\
\hline Allows me to watch whenever I want & 15 & 2 & 9 & 2 & 9 & 9 \\
\hline Allows me to use wherever I want & 10 & 1 & 12 & 10 & 16 & 8 \\
\hline $\begin{array}{l}\text { Allows me to use in a comfortable } \\
\text { situation }\end{array}$ & 6 & 11 & 5 & 3 & 8 & 6 \\
\hline $\begin{array}{l}\text { Provides the opportunity to watch with } \\
\text { who I want }\end{array}$ & 9 & 15 & 16 & 4 & 3 & 7 \\
\hline Allows me several relevant functions & 4 & 6 & 10 & 8 & 4 & 11 \\
\hline Easily combines with other devices & 12 & 9 & 4 & 11 & 10 & 15 \\
\hline Allows me to search for new content & 11 & 3 & 15 & 16 & 6 & 1 \\
\hline Functions in a reliable fashion & 5 & 10 & 3 & 1 & 13 & 3 \\
\hline Is easy to use & 2 & 8 & 11 & 6 & 7 & 2 \\
\hline Provides high quality sound and images & 7 & 7 & 2 & 9 & 2 & 4 \\
\hline $\begin{array}{l}\text { Allows me to combine with other } \\
\text { activities }\end{array}$ & 8 & 12 & 14 & 5 & 11 & 16 \\
\hline Has an attractive design & 16 & 16 & 6 & 13 & 15 & 5 \\
\hline Gives me my money's worth & 3 & 5 & 1 & 15 & 12 & 13 \\
\hline Helps me figuring out what to watch & 14 & 13 & 7 & 14 & 5 & 10 \\
\hline Is a device ready for future developments & 1 & 14 & 13 & 12 & 14 & 12 \\
\hline
\end{tabular}


Figure 1. Specified structural equation model (see attachment)

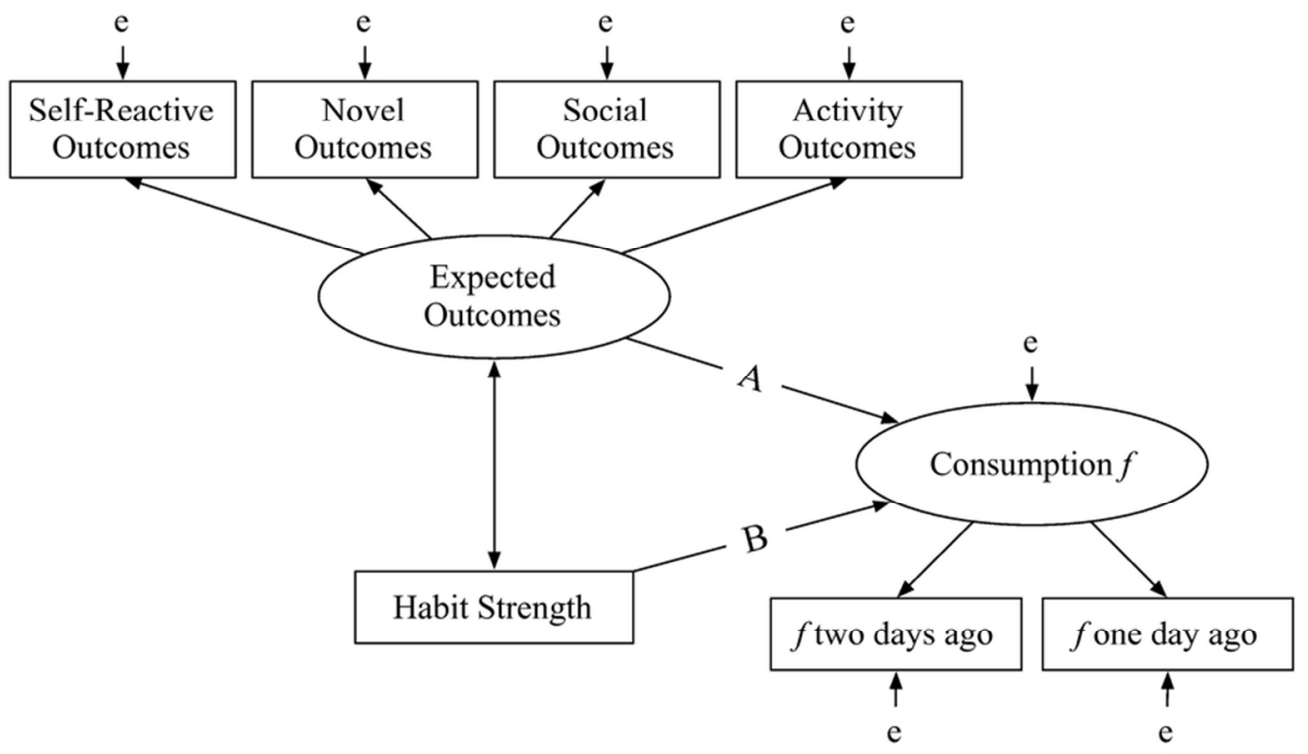

Figure 2. Latent class analysis overview, rescaled to 0-1 to augment interpretability. The higher the score, the more probable it is for respondents in the class to regularly use the screen device (see attachment).

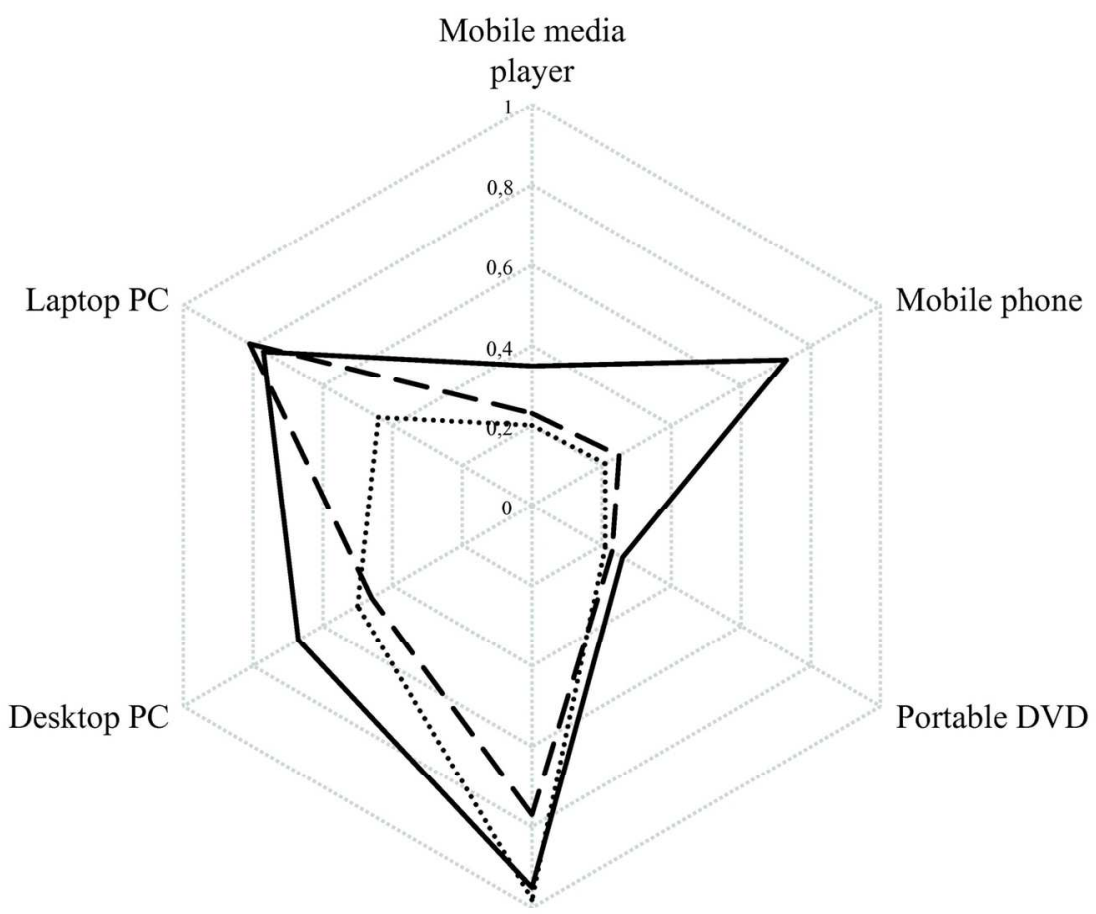

Television 